\title{
Towards a refined mindfulness model related to consciousness and based on ERP
}

Charles VERDONK ${ }^{\left(\mathrm{a}, \mathrm{b},{ }^{*}\right)}$, Marion TROUSSELARD ${ }^{(\mathrm{a}, \mathrm{c})}$, Frédéric CANINI $^{(\mathrm{a}, \mathrm{c})}$, Francois VIALATTE $^{(\mathrm{b})}$, Céline RAMDANI ${ }^{(\mathrm{a})}$

(a) French Armed Forces Biomedical Research Institute

Neurosciences and cognitive sciences Department

Neurophysiology of stress Unit

BP73, 91223 Brétigny-sur-Orge Cedex, France

(b) Ecole Supérieure de Physique et de Chimie Industrielles

PSL Université Recherche

Brain Plasticity Unit - CNRS UMR 8249

Brain Computer Interface Team

10, rue Vauquelin, 75231 Paris cedex 05, France

(c) French Military Health Service Academy

1 Place Alphonse Laveran, 75230 Paris cedex 05, France

\section{*Corresponding author:}

Charles VERDONK

Mail: verdonk.charles@gmail.com 
Verdonk C, Trousselard M, Canini F, Vialatte F, Ramdani C. Toward a refined Mindfulness model related to consciousness and based on ERP. Perspectives on Psychological Science. June 2020. doi: $\underline{10.1177 / 1745691620906444}$ 


\begin{abstract}
Neuroimaging, behavioral and self-report evidence suggests that there are four main cognitive mechanisms that support mindfulness: 1) self-regulation of attention, 2) improved body awareness, 3) improved emotion regulation, and 4) change in perspective on the self. The current paper discusses these mechanisms, based on studies of Event Related Potential (ERP). We review the ERP literature related to mindfulness and examine a dataset of 29 articles. Our findings show that the neural features of mindfulness are consistently associated with the self-regulation of attention and, in most cases, reduced reactivity to emotional stimuli and improved cognitive control. On the other hand, there appear to be no studies of body awareness. We link these electrophysiological findings to models of consciousness, and introduce a unified, mechanistic mindfulness model. The main idea in this refined model is that mindfulness decreases the threshold of conscious access. We end with several working hypotheses that could direct future mindfulness research, and clarify our results.
\end{abstract}

\title{
Keywords
}

Mindfulness; event related potential; consciousness threshold; self-regulation of attention; emotion regulation; cognitive control; body awareness. 


\section{A MINDFULNESS MODEL RELATED TO CONSCIOUSNESS}

Over the past three decades, researchers have highlighted the benefits of mindfulness on health and well-being, and the number of studies on the topic has increased. A search for the term "mindfulness" in the PubMed database found more than 5800 references, the first dating from 1982. A search restricted to 2010-2018 found more than 5300 references, reflecting the substantial increase in interest in recent years. Most studies have investigated the impact of Mindfulness Meditation (MM) on clinical populations, drawing upon programs such as Mindfulness Based Stress Reduction (MBSR) or Mindfulness Based Cognitive Therapy (MBCT) intended to reduce psychological distress and disease-related physical symptoms such as pain (Kabat-Zinn, 1990; Segal, Williams, \& Teasdale, 2012). These studies consistently report an improvement in health (with decreased psychological and physical symptoms) and an increase in well-being (Chiesa \& Serretti, 2011; Fjorback, Arendt, Ørnbøl, Fink, \& Walach, 2011; Goldberg et al., 2018). If the answer to the question "Does mindfulness work?" is clearly positive, the answer to the question "How does mindfulness work?" remains at the frontier of science.

Therefore, the current paper discusses potential mindfulness mechanisms. In particular, we propose a mindfulness model that focuses on conscious access to information. The starting point is Hölzel's model, which is based on neuroimaging, behavioral and self-reported evidence. The latter model describes four main cognitive mechanisms through which mindfulness may work: 1) the self-regulation of attention, 2) change in perspective on the self, 3) enhanced body awareness, and 4) improved emotion regulation (Hölzel et al., 2011).

The aim of our work is to refine this initial model and, in particular, to articulate these four mechanisms with respect to each other. Our refined model suggests that mindfulness: $(i)$ lowers the threshold of conscious access as a function of attentional mechanisms (selfregulation of attention in Hözel's model), and (ii) facilitates the conscious processing of information that comes from from within (body-awareness and self-awareness) and outside 


\section{A MINDFULNESS MODEL RELATED TO CONSCIOUSNESS}

the body (world-awareness). The enhanced body awareness and change in perspective on the self found in Hözel's model may result from improved conscious processing of information from within, while better emotion regulation may be due to improved conscious processing of self-awareness and world-awareness.

Finally, we evaluate our mindfulness model with respect to the current Event Related Potential (ERP) and mindfulness literature.

\section{The significance of ERP studies}

There are two ways to investigate mindfulness mechanisms: ERP and neuroimaging. In this study, we use ERP because the temporal resolution of electroencephalography (Gosseries et al., 2008) renders the method particularly suitable for investigating the very early cognitive mechanisms (from $100 \mathrm{~ms}$ to $600 \mathrm{~ms}$ after information onset) involved in the processing of incoming information. Moreover, conscious access to information seems to occur in a similar temporal window of around 270-300ms (Gaillard et al., 2009).

ERP is computed by recording electrical brain activity locked to a specific event (e.g. the presentation of a stimulus or the participant's motor response). It reflects activity in ensembles of cortical neurons that has a fixed temporal relation to a specific event. Thus, ERP provides information about the participant's cognitive response to a specific event.

Most ERP-based studies of mindfulness have investigated healthy populations, notably MM practitioners and individuals with dispositional mindfulness (i.e. people who are naturally mindful, and do not have a specific MM practice). In theory, this focus on healthy populations makes it possible to investigate mindfulness mechanisms in an, a priori, unaltered brain. 


\section{A MINDFULNESS MODEL RELATED TO CONSCIOUSNESS}

\section{Potential connections between mindfulness models and consciousness models}

Developing a joint mindfulness/consciousness model makes sense as mindfulness and consciousness (within the meaning of conscious awareness) seem to be closely linked. For example, neuroimaging data suggest that some of the brain areas involved in $\mathrm{MM}$ and consciousness (notably the anterior cingulate cortex, the insula, the posterior cingulate cortex, some regions of the prefrontal cortex, and the thalamus) could overlap (Manuello, Vercelli, Nani, Costa, \& Cauda, 2016).

\section{Models of consciousness}

Models of consciousness suggest that the conscious visual perception of a stimulus involves two main processes. The first is bottom-up: the propagation of sensory signals through the visual hierarchy; the second is top-down: attention amplification by late, higherlevel integrative processes. Sensory information is continuously processed in an unconscious manner, while conscious access is thought to start when attention amplifies a given piece of information, allowing it to access a network of high-level brain regions that are broadly interconnected by long-range connections (Baars, 1993; De Lafuente \& Romo, 2006; Dehaene, 2011; Dehaene \& Changeux, 2011). This so-called global neuronal workspace integrates incoming information into the current, conscious context where it becomes available to other neural processes. Conscious access to incoming sensory evidence has been linked to a "decision to engage" the global workspace (Dehaene, Izard, Spelke, \& Pica, 2008; Shadlen \& Kiani, 2011).

According to these theoretical models, an elevated consciousness threshold could result from a bottom-up perceptual impairment (the object remains subliminal) and/ or a lack of topdown attentional amplification (the object remains preconscious) (Dehaene, Changeux, Naccache, Sackur, \& Sergent, 2006), preventing conscious access to information (Berkovitch, 


\section{A MINDFULNESS MODEL RELATED TO CONSCIOUSNESS}

Del Cul, Maheu, \& Dehaene, 2018). Conversely, it seems reasonable to assume that attentional amplification could result in a lower consciousness threshold. As mindfulness aims to enhance attentional skills (notably the self-regulation of attention, which includes focused attention), we suggest that the consciousness threshold can be adjusted by modulating the process of attention amplification, as described in theoretical models of conscious processing (Dehaene \& Changeux, 2004, 2011). By promoting attentional skills, mindfulness could lower the consciousness threshold and consequently facilitate world-awareness (awareness of the external world), self-awareness (awareness of thoughts and emotions) and body-awareness (interoception). In other words, mindfulness could help to overcome the situation where information from the world, the self and the body remains preconscious, by facilitating the conscious processing of this information.

In the next section, we link the mechanisms presented in Hözel's mindfulness model (Hölzel et al., 2011) to our refined model.

\section{Self-regulation of attention}

The practice of mindfulness aims to enhance the self-regulation of attention. The latter relies on two cognitive abilities: focused attention and/ or open monitoring (Lutz, Jha, Dunne, \& Saron, 2015). Focused attention enables individuals to deliberately access an extensive sensory experience, and is primarily based on breathing. Open monitoring enhances the ability of individuals to adopt a non-judgmental attitude to anything that they experience (Lutz, Slagter, Dunne, \& Davidson, 2008; Malinowski, 2013). We suggest that the selfregulation of attention per se could support the top-down process of attentional amplification, as described in models of consciousness. 


\section{A MINDFULNESS MODEL RELATED TO CONSCIOUSNESS}

\section{Change in perspective on the self}

As Hölzel et al. (2011) stated, change in perspective on the self is difficult to define. The latter authors describe the self as "being the one who inhabits the body, being the one who is thinking the thoughts, being the one experiencing emotions, and being the agent of actions" (Hölzel et al., 2011, p. 547). It can be considered as emerging from a specific brain activity that produces thoughts, emotions, and actions.

The perception of a self leads to the development of meta-awareness. Meta-awareness, in turn, contributes to cognitive control by orienting attention towards the contents of conscious experience and associated processes (Hölzel et al., 2011; Schooler, 2002).

In mindfulness, change in perspective on the self could result from focused attention on self-activities. By bringing the content of experience (i.e. thoughts and emotions) to consciousness, mindful functioning could improve cognitive control through the selection of the most relevant information. Such information could contribute to resolving conflicts, leading to action, and response inhibition or adjustment.

\section{Enhanced body-awareness}

Mindfulness practice relies on training the mind to pay sustained attention to the body experience, primarily the breath, and deliberately returning attention to it whenever distracted (Lutz et al., 2015). Body-awareness refers to the ability to feel engaged by information coming from the body and to notice subtle changes (Mehling et al., 2009). Such information informs individuals about both their internal physiological state (interoception) and their body in relation to space and movement (exteroception) (Craig, 2002; Mehling et al., 2009; Valenzuela-Moguillansky, Reyes-Reyes, \& Gaete, 2017).

The enhanced body awareness resulting from mindfulness could be due to focusing the attention on the body, which facilitates conscious access to increasingly subtle physical 


\section{A MINDFULNESS MODEL RELATED TO CONSCIOUSNESS}

sensations. Body awareness has been found to increase after mindfulness practice and is associated with dispositional mindfulness (Carmody \& Baer, 2008; Farb et al., 2015; Hanley,

Mehling, \& Garland, 2017; Mehling et al., 2012; Treves, Tello, Davidson, \& Goldberg, 2019).

\section{Improved emotion regulation}

Emotion regulation could be defined as the ability to modify the intensity and duration of emotional responses in the context of meeting goals and managing arousal (Thompson, 1994). It may also extend to the ability to modify the emotion's significance, as cognitive strategies can alter how emotional stimuli are attended to and interpreted (Dennis \& Hajcak, 2009).

In the context of mindfulness, it is thought to rely on two cognitive strategies: "positive reappraisal" and "extinction" (Hölzel et al., 2011, p. 543). Reappraisal is a cognitive strategy that seeks to reinterpret an emotional situation in a different way (Hajcak \& Nieuwenhuis, 2006), and it assumes there is conscious access to emotional content. Extinction refers to an active effort to limit internal engagement when exposed to negative emotions, reducing avoidance and leading to the reversal of stimulus-response conditioning (Chambers, Gullone, \& Allen, 2009; Garland, Gaylord, \& Fredrickson, 2011; Hölzel et al., 2011). Mindfulness has been associated with decreased reactivity to both negative and positive emotions - in other words, improved emotion regulation (Guendelman, Medeiros, \& Rampes, 2017). The amplification of attention, and the subsequent facilitation of conscious access may explain this ability to deal with emotions in a non-judgmental manner. 


\section{A MINDFULNESS MODEL RELATED TO CONSCIOUSNESS}

\section{Method}

Our literature review followed Preferred Reporting Items for Systematic Reviews and Meta-Analyses (PRISMA) guidelines (Moher, Liberati, Tetzlaff, \& Altman, 2009). The initial dataset consisted of the Scopus, PubMed, Google Scholar and APA PsychNET online databases. Search criteria were: "mindfulness" AND "event related potential" in: $(i)$ the article's title, abstract and keywords in Scopus; (ii) the article's title and abstract in PubMed; (iii) the article's title in Google Scholar; and (iv) the abstract in APA PsychNET. We considered publications from 1990 (the year Kabat-Zinn's book on mindfulness was published) to 1 October 2018. Regarding participants, interventions, comparisons, outcomes and study design (PICOS) characteristics, the key criteria were: adults (for participants); mindfulness (for interventions); and ERPs (for outcomes). All articles were published in English.

Inclusion criteria were: $(i)$ that the article directly addressed the topic of mindfulness, or an equivalent meditation practice (i.e. Vipassana, Zen, or Buddhist meditation); (ii) ERPs were recorded in relation to mindfulness; and (iii) the study examined a sample of adults. Exclusion criteria were theoretical articles, commentaries or editorials.

The following variables were extracted from each article: $(i)$ mindfulness components (i.e. $\mathrm{MM}$ intervention, mindfulness-based clinical program, MM practice or dispositional mindfulness); (ii) participants' experience of their MM practice (duration and frequency); (iii) population features (healthy or clinical); (iv) the experimental design (mindfulness and control groups), measurement time (pre- and post-intervention) and experimental tasks; and (v) ERP outcomes (amplitude, latency).

The main measurements were differences in ERP amplitude between either: (i) mindfulness (MM intervention, mindfulness-based clinical program or healthy meditators) 


\section{A MINDFULNESS MODEL RELATED TO CONSCIOUSNESS}

and control (control or non-meditator groups) conditions; (ii) levels of dispositional mindfulness; or (iii) mindfulness meditative and mind-wandering conditions.

\section{Results and discussion}

ERP studies of mindfulness have investigated cognitive control, the regulation of attention, and emotion regulation. Our review did not find any ERP studies that investigated the body-awareness mechanism. For the sake of clarity, we have combined the presentation and discussion of our results with respect to each mechanism separately.

\section{Search results}

Our review initially identified 68 citations (39 from the Scopus database, 23 from PubMed, five from Google Scholar and one from APA PsychNET). After the removal of duplicates, 55 articles were considered as relevant. A review of the abstracts led to the exclusion of 26 articles. Nine were not research articles, four were not related to mindfulness, five did not record ERP in relation to mindfulness, five were not carried out in an adult population, and three were not published. The final dataset consisted of 29 articles (Figure 1).

\section{General description of ERP studies}

Eleven articles investigated the self-regulation of attention, and were based on 11 independent samples $(\mathrm{n}=357$; age $=17-80)($ Table 1$)$. Twelve articles investigated cognitive control, based on 12 independent samples $(n=545$; age $=17-80)$ (Table 2). It should be noted that four studies investigated both the self-regulation of attention and cognitive control 


\section{A MINDFULNESS MODEL RELATED TO CONSCIOUSNESS}

(Atchley et al., 2016; Malinowski, Moore, Mead, \& Gruber, 2017; Moore, Gruber, Derose, \& Malinowski, 2012; Norris, Creem, Hendler, \& Kober, 2018). Lastly, 10 articles focused on emotion regulation in 10 independent samples $(n=411$; age $=18-70)($ Table 3$)$.

As four articles were based on overlapping samples (Howells, Ives-Deliperi, Horn, \& Stein, 2012; Howells, Laurie Rauch, Ives-Deliperi, Horn, \& Stein, 2014; Smart \& Segalowitz, 2017; Smart, Segalowitz, Mulligan, Koudys, \& Gawryluk, 2016), our dataset of 29 articles drew upon results from 27 independent samples $(n=1185$; age $=17-80)$. Participants were either healthy subjects (22 independent samples, $\mathrm{n}=954$; age $=17-80$ ) or patients (five independent samples, $\mathrm{n}=231$; age $=18-80$ ). In the latter case, patients were either depressed (Bostanov, Keune, Kotchoubey, \& Hautzinger, 2012, n = 64), bipolar (Howells et al., 2012; Howells et al., 2014, $\mathrm{n}=12$ ), suffering from chronic pain and at risk of opioid abuse (Garland, Froeliger, \& Howard, 2015, n = 29), suffering from attention-deficit/ hyperactivity disorders (Schoenberg et al., 2014, $\mathrm{n}=50$ ), or subjective cognitive decline in older adults (Smart \& Segalowitz, 2017; Smart et al., 2016, $\mathrm{n}=76$ ).

Our results can be categorized into: (i) studies examining change in ERP amplitude in relation to $\mathrm{MM}$ practice (MM interventions, mindfulness-based clinical programs and healthy meditators); (ii) studies examining modulation in ERP amplitude as a function of dispositional mindfulness; and (ii) studies focusing on the effects of a mindful state in comparison to a mind-wandering state or a control condition (Tables 1-4).

\section{Regulation of attention}

\section{Results}

Two components were investigated in relation to the regulation of attention: P300, and Contingent Negative Variation (CNV). 


\section{A MINDFULNESS MODEL RELATED TO CONSCIOUSNESS}

P300. P300 was the main ERP of interest in studies focused on attention and was reported in 10 of the 11 articles $(91 \%)$. The late (P3b) component was more frequently investigated than the early (P3a) component (9 out of 10 articles).

$\mathrm{P} 3 \mathrm{a}$ reflects automatic attention attraction and can occur in a non-conscious way (MullerGass, Macdonald, Schröger, Sculthorpe, \& Campbell, 2007). Conversely, P3b, which occurs about $300-500 \mathrm{~ms}$ after stimulus onset, is thought to be a signature of conscious perception (for a review, see Dehaene \& Changeux, 2011). Although the association with consciousness is challenged, P3b is thought to be related to the frontoparietal network that plays a key role in task monitoring and reporting (Koch, Massimini, Boly, \& Tononi, 2016).

In most cases, mindfulness was associated with greater P3b amplitude in tasks based on attention to task-relevant stimuli (e.g. tones in an auditory oddball task) (Atchley et al., 2016; Delgado-Pastor, Perakakis, Subramanya, Telles, \& Vila, 2013; Lakey, Berry, \& Sellers, 2011; Smart et al., 2016). This observation was found: $(i)$ in experienced meditators at rest (relative to naïve meditators) (Atchley et al., 2016) and after 30 minutes of MM practice (DelgadoPastor et al., 2013); (ii) after eight weeks of MM training in a clinical population with subjective cognitive decline (Smart et al., 2016); and (iii) after a very brief mindfulness intervention (six minutes) in a healthy population (Lakey et al., 2011). On the other hand, two studies failed to detect a positive effect of mindfulness on the P3b component (Malinowski et al., 2017; Norris et al., 2018). The P3b component was also investigated in response to irrelevant (to the task) stimuli introduced as distractors. In this case, lower P3b amplitude was reported in meditators (Atchley et al., 2016), after a mindfulness intervention (eight weeks, 16 weeks, or three months) in a healthy population (Moore et al., 2012; Slagter et al., 2007), and in a clinical population with bipolar disorder (Howells et al., 2012). Finally, the amplitude of the early P3a component was found to be lower in a meditative state than in a mind- 


\section{A MINDFULNESS MODEL RELATED TO CONSCIOUSNESS}

wandering state, and this observation was positively correlated with MM practice frequency (Cahn \& Polich, 2009).

Contingent Negative Variation. In a sequence of paired warning-imperative stimuli, CNV amplitude is positively correlated with the subjective probability of the imperative stimuli (Walter, Cooper, Aldridge, McCallum, \& Winter, 1964). The CNV is related to response preparation, attention and arousal level, as its cerebral generators include motor, premotor and other cortex areas (Tecce, 1972; Tecce \& Cattanach, 1993).

Only one article investigated CNV in mindfulness, and its amplitude was increased after an eight-week MBCT intervention in recurrently depressed patients (Bostanov et al., 2012).

\section{Discussion}

If $\mathrm{P} 3 \mathrm{~b}$ is the electrophysiological sign of conscious access, an increase in amplitude should indicate better access to consciousness. The larger P3b amplitude found in mindfulness experiments (Atchley et al., 2016; Delgado-Pastor et al., 2013; Lakey et al., 2011; Smart et al., 2016) supports the hypothesis that mindfulness decreases the threshold of conscious access. However, at the same time, mindfulness was also associated with lower P3b amplitude in response to task-irrelevant stimuli (i.e. a distractor) (Atchley et al., 2016; Howells et al., 2012; Moore et al., 2012; Slagter et al., 2007). Finally, task-relevant stimuli were found to elicit higher CNV amplitude in a mindfulness condition (Bostanov et al., 2012).

Taken together, these findings suggest that better conscious access to information in mindfulness (through a process of attentional amplification) could be solely oriented towards goal-relevant information.

In the context of the global neuronal workspace model (Baars, 1993; De Lafuente \& Romo, 2006; Dehaene, 2011; Dehaene \& Changeux, 2011), conscious access is related to a 


\section{A MINDFULNESS MODEL RELATED TO CONSCIOUSNESS}

"decision to engage" the global workspace when faced with incoming information (Dehaene et al., 2008; Shadlen \& Kiani, 2011). Bringing information to consciousness could be viewed as a decisional process, a choice between leaving information unconscious or helping it to reach consciousness. It could be argued that, when the stimulus is goal-irrelevant, the decision should be to keep it unconscious. The idea of a lower threshold of conscious access is congruent with this hypothesis, because attentional amplification helps to keep information under the threshold or bring it above the threshold depending on its relevance to the context. Moreover, an early decision to bring information to consciousness (or not) avoids blocking conscious access and prevents information loss due to the Psychological Refractory Period ${ }^{1}$ (Marti, Sigman, \& Dehaene, 2012).

To summarize, attentional amplification (which lowers the conscious access threshold) could be associated with an attentional focus on pertinent information, at the expense of nonpertinent information. The upshot of this could be an optimization that seeks to fill the global neural workspace with pertinent information and avoid saturation with irrelevant information, thus enabling more fluent, effortless thinking.

Furthermore, mindfulness is negatively associated with P3a amplitude (Cahn \& Polich, 2009). P3a reflects the automatic capture of attention by any new stimulus (stimulus-driven attention) and can occur unconsciously (Muller-Gass et al., 2007; Polich, 2007). We suggest that mindful functioning is characteristic of unbiased information processing that operates via the disengagement of the attentional system to stimulus-driven activation. In other words, the attentional system could be similarly engaged for all stimuli irrespective of their novelty, and without any expectations (i.e. an unexpected stimulus could merely be interpreted as a novel one without any implication of automatic attention). This engagement of automatic attention

\footnotetext{
${ }^{1}$ Doing two things at once is difficult. When two tasks have to be performed within a short interval, the second is significantly delayed, an effect known as the Psychological Refractory Period.
} 


\section{A MINDFULNESS MODEL RELATED TO CONSCIOUSNESS}

can be compared to the non-judgmental attitude that contributes to the definition of mindfulness (Kabat-Zinn, 1990, 1994).

To sum up, mindful functioning could allow the unconscious and unbiased processing of incoming information. Attentional amplification may facilitate relevant information reaching the consciousness to the detriment of irrelevant information. This trade-off is illustrated in the finding that P3a and P3b amplitudes oppose each other.

\section{Cognitive control}

\section{Results}

The 12 studies of cognitive control mainly focused on the following three ERPs: $(i)$ the N2 component (six articles, 50\%), (ii) Error-related negativity (seven articles, 58\%), and (iii) the Positivity error (five articles, 42\%). An additional ERP - the no-go P3 component was investigated in two articles.

N2. The N2 component peaks between 200 and $350 \mathrm{~ms}$ after stimulus onset. As its amplitude is sensitive to a mismatch between a stimulus and a mental template, it is thought to be a conflict monitoring index (Bruin, Wijers, \& Van Staveren, 2001; Donkers \& Van Boxtel, 2004; Nieuwenhuis, Yeung, Van Den Wildenberg, \& Ridderinkhof, 2003). It may also be driven by the inhibition of a planned response (for a review, see Folstein \& Van Petten, 2008).

Our review found that mindfulness was mainly associated with increased N2 amplitude (Atchley et al., 2016; Malinowski et al., 2017; Moore et al., 2012; Norris et al., 2018; Quaglia, Goodman, \& Brown, 2016). Specifically: (i) amplitude was positively correlated with dispositional mindfulness (Quaglia et al., 2016), (ii) its amplitude was higher in experienced than naïve meditators (Atchley et al., 2016), and (iii) higher following MM interventions (10 minutes, 8 or 16 weeks) in a healthy population (Malinowski et al., 2017; Moore et al., 2012; 


\section{A MINDFULNESS MODEL RELATED TO CONSCIOUSNESS}

Norris et al., 2018). Only one study failed to detect a positive effect of mindfulness (Schoenberg et al., 2014).

Error-related negativity and error positivity. Error-related negativity (ERN) (Gehring, Goss, Coles, Meyer, \& Donchin, 1993), also known as "error negativity" (Falkenstein, Hohnsbein, Hoormann, \& Blanke, 1991), peaks around 100ms after the electromyographic response. ERN is a well-established index of action monitoring (Holroyd \& Coles, 2002). Moreover, recent work suggests that it reflects an internal comparison between two signals: an unconscious representation of the ongoing action and a conscious representation of the intended action (Dehaene, 2018). ERN is followed by Error Positivity ${ }^{2}$ (Pe), which occurs about 200-500ms after an error (Falkenstein et al., 1991; Overbeek, Nieuwenhuis, \& Ridderinkhof, 2005). Pe amplitude is larger for consciously-perceived than unperceived errors (Endrass, Reuter, \& Kathmann, 2007; Murphy, Robertson, Allen, Hester, \& O'Connell, 2012; Nieuwenhuis, Ridderinkhof, Blom, Band, \& Kok, 2001). The Pe component is, therefore, believed to reflect error awareness (Steinhauser \& Yeung, 2010; Ullsperger, Danielmeier, \& Jocham, 2014).

In contrast to $\mathrm{N} 2$ findings, only $33 \%$ of studies reported higher ERN amplitude in mindfulness. In the same way, only $20 \%$ of studies reported higher Pe amplitude in mindfulness (Schoenberg et al., 2014; Smart \& Segalowitz, 2017; Teper \& Inzlicht, 2012). Although experienced meditators were found to have a higher ERN amplitude than naïve meditators, this was not found for the Pe component (Teper \& Inzlicht, 2012). A very brief mindfulness intervention (15 minutes) has been found to lead to an increase, a decrease, and no change - depending on the ERP component and the study (Bing-Canar, Pizzuto, \&

\footnotetext{
${ }^{2}$ ERN and Pe seem to be generated by independent structures and reflect two independent systems of error monitoring (Di Gregorio, Steinhauser, \& Maier, 2016).
} 


\section{A MINDFULNESS MODEL RELATED TO CONSCIOUSNESS}

Compton, 2016; Larson, Steffen, \& Primosch, 2013; Saunders, Rodrigo, \& Inzlicht, 2016). The same finding was observed for MM interventions in clinical populations. A 12-week MBCT intervention in patients with attention deficit/ hyperactivity disorders was found to increase the Pe component, without modifying ERN and N2 components (Schoenberg et al., 2014). At the same time, an 8-week MM training program in a population of older adults with subjective cognitive decline increased ERN amplitude without changing the Pe component (Smart \& Segalowitz, 2017).

No-go P3. The no-go P3 component emerges in the frontocentral region 300-600ms after stimulus presentation and reflects response inhibition (Falkenstein, Hoormann, Christ, \& Hohnsbein, 2000; Salisbury, Griggs, Shenton, \& McCarley, 2004). Our review found that mindfulness was consistently associated with higher no-go P3 amplitude (Quaglia et al., 2016; Schoenberg et al., 2014).

\section{Discussion}

The enhanced cognitive control found in mindfulness is thought to be a consequence of an increase in self-awareness (i.e. increased conscious processing of thoughts and emotions) and world-awareness (i.e. better conscious access to information from the external world).

The findings from ERP studies support this hypothesis, as N2 amplitude is higher in mindfulness (Atchley et al., 2016; Malinowski et al., 2017; Moore et al., 2012; Norris et al., 2018; Quaglia et al., 2016). However, results based on the ERN component are puzzling. Our model could predict either a decrease or an increase in ERN amplitude in mindfulness, depending on the functional significance. On the one hand, if we adopt the position of better 


\section{A MINDFULNESS MODEL RELATED TO CONSCIOUSNESS}

world-awareness, consistent with Dehaene's hypothesis ${ }^{3}$ regarding ERN functional significance, our model predicts that mindfulness would increase ERN amplitude by improving the conscious representation of the intended action (Dehaene, 2018). On the other hand, mindfulness could decrease ERN amplitude following an emotion reappraisal strategy (Hölzel et al., 2011), because ERN amplitude is reduced when negative emotions are attenuated through cognitive reappraisal (Hobson, Saunders, Al-Khindi, \& Inzlicht, 2014). Concerning the Pe component, although the reviewed evidence is mixed, our model assumes greater error awareness in mindfulness and predicts an increase in Pe amplitude.

Finally, mindfulness could also improve cognitive control through better inhibition, as reflected in the enhanced no-go P3 component (Quaglia et al., 2016; Schoenberg et al., 2014). ERP findings are consistent with behavioral evidence showing improved performance in the Stroop task by experienced meditators relative to naïve meditators (Chan \& Woollacott, 2007; Moore \& Malinowski, 2009), or after a MM intervention (Wenk-Sormaz, 2005).

\section{Emotion regulation}

\section{Results}

Three components were investigated in relation to emotion regulation: the Late Positive Potential, N170 and P600.

Late Positive Potential. The Late Positive Potential (LPP) was the main ERP of interest in the reviewed studies (10 articles, 91\%). It occurs around 400-600ms post-stimulus and refers to the P3b component in situations with emotional stimuli (Schupp, Flaisch,

\footnotetext{
${ }^{3}$ According to Dehaene (2018) the ERN reflects an internal comparison between two signals: an unconscious representation of the ongoing action and a conscious representation of the intended one.
} 


\section{A MINDFULNESS MODEL RELATED TO CONSCIOUSNESS}

Stockburger, \& Junghöfer, 2006). LPP is enhanced in subjects watching emotionally arousing vs neutral pictures. Moreover, Foti et al (2008) demonstrated that LPP amplitude following exposure to unpleasant pictures is reduced when a more neutral interpretation of the picture is given. Therefore, the reduction in LPP following a directed, positive reappraisal may reflect reduced emotional reactivity due to a strategy of emotion regulation (Foti \& Hajcak, 2008).

In three ERP studies, mindfulness was associated with lower LPP amplitude in response to negative and positive emotional stimuli (Brown, Goodman, \& Inzlicht, 2013; Lin, Fisher, Roberts, \& Moser, 2016; Sobolewski, Holt, Kublik, \& Wrobel, 2011). More precisely: (i) higher dispositional mindfulness was associated with lower LPP amplitude (Brown et al., 2013; Lin et al., 2016), (ii) LPP amplitude was lower in experienced compared to naïve meditators (Sobolewski et al., 2011), and (iii) MM interventions in a healthy population were associated with a decrease in LPP amplitude (Lin et al., 2016). On the other hand, mindfulness was associated with higher LPP amplitude in two studies (Egan, Hill, \& Foti, 2018; Uusberg, Uusberg, Talpsep, \& Paaver, 2016), and three studies reported no effect (Cosme \& Wiens, 2015; Ho, Sun, Ting, Chan, \& Lee, 2015; Lin et al., 2016). It should be noted that two studies found a mixed effect of mindfulness on the LPP component, depending on the experimental condition (dispositional mindfulness, meditative state or $\mathrm{MM}$ intervention) (Egan et al., 2018; Lin et al., 2016).

N170 and P600. The amplitude of N170 (also known as the "face potential") and P600 components varies positively with emotional salience and valence, reaching a maximum in response to salient, negative stimuli (Bentin, Allison, Puce, Perez, \& McCarthy, 1996; Holt, Lynn, \& Kuperberg, 2009; Schupp et al., 2000).

Our review found that dispositional mindfulness was negatively associated with P600 amplitude (Dorjee, Lally, Darrall-Rew, \& Thierry, 2015), and a MM intervention was found 


\section{A MINDFULNESS MODEL RELATED TO CONSCIOUSNESS}

to be associated with a decrease in N170 amplitude, at least in a clinical population with bipolar disorder (Howells et al., 2014).

\section{Discussion}

Reduced reactivity to emotion. Our mindfulness model assumes that the extinction strategy (i.e. active limitation of emotional reactivity) could be supported by increased selfawareness.

ERP evidence shows that the intensity of the emotional response is: (i) negatively correlated with dispositional mindfulness (Brown et al., 2013; Dorjee et al., 2015; Lin et al., 2016), (ii) lower in experienced than in naïve meditators (Sobolewski et al., 2011), and (iii) decreases after MM interventions both in healthy (Lin et al., 2016) and clinical populations (Howells et al., 2014). This negative effect of mindfulness on emotional response supports the notion of extinction in mindful functioning. However, the effect was not observed in the case of a task-induced state of mindfulness, where participants were instructed to pay attention to emotional stimuli with a mindful mindset. In this case, an increase in emotional response (Egan et al., 2018; Uusberg et al., 2016) or a lack of change has been reported (Lin et al., 2016). These mixed findings suggest that outcomes could be a function of the experimental context. In particular, it is possible that naïve participants mobilize attentional resources in order to adopt a mindful mindset when faced with emotional stimulation; this would account for their higher emotional reactivity associated with a task-induced state of mindfulness.

Emotion regulation and consciousness in mindfulness. In mindfulness, attention focuses on whatever is experienced, including emotions and related physical changes (e.g. increased heart rate, vasomotor flush) (Hölzel et al., 2011). 


\section{A MINDFULNESS MODEL RELATED TO CONSCIOUSNESS}

Our model suggests that mindfulness supports the conscious processing of emotional significance and its re-evaluation, based on reappraisal and extinction strategies. Mindfulness could involve dissociation from emotion, defined in terms of physical change, and the significance given to it. We suggest that the reduced emotional reactivity found in mindfulness could reflect an increased ability to dissociate an emotion from its significance. More than a "reappraisal", this strategy could be seen as an "appraisal", because no significance is initially attributed to the emotion.

The uncoupling of an emotion from its significance could account for the notion of "acceptance" that contributes to the definition of mindfulness (Kabat-Zinn, 1990, 1994). Acceptance can be defined as an objective, non-reactive lens through which momentary experience is viewed. Regardless of the content of the sensory experience, the individual is encouraged to adopt a mental attitude of acceptance, and allow all experiences - even difficult or stressful ones - to arise and pass without further elaboration, evaluation, or reactivity (Lindsay \& Creswell, 2018).

\section{Enhanced body awareness in mindfulness.}

In our model, improved body awareness may arise from bodily information having better access to consciousness. Our review highlighted that no ERP studies of mindfulness have investigated this topic.

Classically, objective measures of body awareness are peripheral (e.g. heartbeat detection, skin conductance arousal, respiratory tracking, joint position sense, etc.) (Treves et al., 2019), but some central signals could be of interest. For instance, the Heartbeat Evoked Potential is an ERP that occurs about 200-600ms after the cardiac R-wave signal (Schandry, Sparrer, \& Weitkunat, 1986). Its amplitude is consistently reported to be a good predictor of individual performance in a heartbeat detection task (Pollatos, Kirsch, \& Schandry, 2005; Pollatos \& 


\section{A MINDFULNESS MODEL RELATED TO CONSCIOUSNESS}

Schandry, 2004; Schandry et al., 1986). Perception awareness can be evaluated using pN1 and pP1, which reflect sensory awareness and awareness of sensory-motor integration, respectively (Perri et al., 2018). Respiratory movements and postural balance are other interesting candidates, because these physical signals exhibit periodic oscillations that make them particularly suited to analyzing time-locked brain activity (Winter, 1995; Zelano et al., 2016).

Future studies should probe these physiological markers to investigate the enhanced body awareness mechanism though which mindfulness may work.

Furthermore, we suggest that enhanced body awareness in mindfulness could play a major role, as effective body-to-brain communication could foster emotion regulation and cognitive control. The literature suggests that bodily information plays a major role in the way individuals regulate their emotions (Damasio, 1996; Dunn et al., 2010; Magalhaes, Oliveira, Pereira, \& Menezes, 2018). Here, we suggest that enhanced body awareness could improve cognitive control by contributing to building the self (i.e. thoughts or emotions) and developing meta-awareness. Studies have revealed that only a third of partial errors ${ }^{4}$ are consciously detected (Rochet, Spieser, Casini, Hasbroucq, \& Burle, 2014). Our model suggests that mindfulness could improve the conscious perception of partial errors, and support their correction before they turn into overt errors.

\section{What is the "half-life" of mindfulness?}

Investigation of mindfulness efficacy and its mechanisms raises the following question: "What is the half-life of mindfulness?", in analogy to the half-life of a drug. In this section,

\footnotetext{
${ }^{4}$ Partial errors are electromyographic activations that occur on the non-required side of the response; they are detected, inhibited, and corrected before they reach the mechanical response threshold. They have been considered as peripheral electrophysiological markers of cognitive control (Burle, Possamai, Vidal, Bonnet, \& Hasbroucq, 2002; Smid, Mulder, \& Mulder, 1990).
} 


\section{A MINDFULNESS MODEL RELATED TO CONSCIOUSNESS}

we discuss the short- (time-limited) and/ or long-term (persistent over time) effects of mindfulness on cognition.

Our review of ERP findings showed that neural features of attention can be detected very early in MM practice, after only a few minutes (Lakey et al., 2011). This quick effect is consistent with the early phases of MM practice that specifically address focused attention (Chiesa, Calati, \& Serretti, 2011). But does the effect persist over time? If not, it could be argued that effects reported after long-term interventions (MBSR, MBCT) (Fjorback et al., 2011) could merely be the consequence of the participant's most recent session.

It should be noted that in most of the reviewed studies, the cognitive task was performed immediately after the mindfulness intervention. Furthermore, when assessing experienced meditators, the interval between the cognitive assessment and the most recent meditative session was not controlled. Consequently, it could be argued that the mindfulness effect reported in experienced meditators could be the result of the session undertaken just before the experiment. Therefore, we suggest that future work should control for the timing of the cognitive task with respect to the mindfulness intervention (or practice for experienced meditators). This precaution should provide a better understanding of the short- and/ or longterm characteristics of the effect of mindfulness.

It is important to note that the point discussed above is slightly different to understanding the effect of mindfulness expertise in terms of length of practice (frequency and duration). ERP evidence suggests that long-term mindfulness practice is positively correlated with improvement in cognitive control (Atchley et al., 2016; Teper \& Inzlicht, 2012). Long-term practice is also associated with an inverted u-shaped cerebral activation curve in the attentional network (Brefczynski-Lewis, Lutz, Schaefer, Levinson, \& Davidson, 2007). These findings suggest that, even though the development of mindful cognitive abilities is resource- 


\section{A MINDFULNESS MODEL RELATED TO CONSCIOUSNESS}

consuming, mindful functioning is beneficial because it becomes more economical with the level of expertise.

\section{Conclusion}

Our work aims to develop a refined model of mindfulness in relation to consciousness. This extended model was evaluated using the existing ERP literature. Our model suggests that mindfulness decreases the threshold of conscious access by supporting attention (Figure 2). Mindfulness, therefore, facilitates the conscious processing of information that comes from within (body-awareness and self-awareness) and outside the body (world-awareness).

Our work seeks to articulate the cognitive mechanisms associated with mindfulness in relation to each other, taking the self-regulation of attention as a starting point. It seems that as bodily information has better access to consciousness, body awareness improves. Our model suggests that these first two mechanisms (self-regulation of attention and enhanced body awareness) contribute to better cognitive control and emotion regulation. We argue that effective body-to-brain communication, combined with better access to consciousness supports the processing of emotion and its appraisal, thus reducing reactivity. Finally, the individual's representation of the intended action with respect to the context is improved by the conscious processing of information from within and in the external world, thus supporting the control of ongoing action and its outcomes. 


\section{References}

Atchley, R., Klee, D., Memmott, T., Goodrich, E., Wahbeh, H., \& Oken, B. (2016). Eventrelated potential correlates of mindfulness meditation competence. Neuroscience, 320, 83-92.

Baars, B. J. (1993). A cognitive theory of consciousness: Cambridge University Press.

Bentin, S., Allison, T., Puce, A., Perez, E., \& McCarthy, G. (1996). Electrophysiological studies of face perception in humans. Journal of Cognitive Neuroscience, 8(6), 551565.

Berkovitch, L., Del Cul, A., Maheu, M., \& Dehaene, S. (2018). Impaired conscious access and abnormal attentional amplification in schizophrenia. Neuroimage Clin, 18, 835848. doi:10.1016/j.nicl.2018.03.010

Bing-Canar, H., Pizzuto, J., \& Compton, R. J. (2016). Mindfulness-of-breathing exercise modulates EEG alpha activity during cognitive performance. Psychophysiology, 53(9), 1366-1376.

Bostanov, V., Keune, P. M., Kotchoubey, B., \& Hautzinger, M. (2012). Event-related brain potentials reflect increased concentration ability after mindfulness-based cognitive therapy for depression: a randomized clinical trial. Psychiatry Res, 199(3), 174-180. doi:10.1016/j.psychres.2012.05.031

Brefczynski-Lewis, J. A., Lutz, A., Schaefer, H. S., Levinson, D. B., \& Davidson, R. J. (2007). Neural correlates of attentional expertise in long-term meditation practitioners. Proceedings of the National Academy of Sciences, 104(27), 11483-11488.

Brown, K. W., Goodman, R. J., \& Inzlicht, M. (2013). Dispositional mindfulness and the attenuation of neural responses to emotional stimuli. Soc Cogn Affect Neurosci, 8(1), 93-99. doi:10.1093/scan/nss004

Bruin, K. J., Wijers, A. A., \& Van Staveren, A. S. J. (2001). Response priming in a go/nogo task: do we have to explain the go/nogo N2 effect in terms of response activation instead of inhibition? Clinical Neurophysiology, 112(9), 1660-1671.

Burle, B., Possamai, C. A., Vidal, F., Bonnet, M., \& Hasbroucq, T. (2002). Executive control in the Simon effect: an electromyographic and distributional analysis. Psychol Res, 66(4), 324-336. doi:10.1007/s00426-002-0105-6

Cahn, B. R., \& Polich, J. (2009). Meditation (Vipassana) and the P3a event-related brain potential. Int J Psychophysiol, 72(1), 51-60. doi:10.1016/j.ijpsycho.2008.03.013

Carmody, J., \& Baer, R. A. (2008). Relationships between mindfulness practice and levels of mindfulness, medical and psychological symptoms and well-being in a mindfulnessbased stress reduction program. Journal of Behavioral Medicine, 31(1), 23-33.

Chambers, R., Gullone, E., \& Allen, N. B. (2009). Mindful emotion regulation: An integrative review. Clinical Psychology Review, 29(6), 560-572.

Chan, D., \& Woollacott, M. (2007). Effects of level of meditation experience on attentional focus: is the efficiency of executive or orientation networks improved? The Journal of Alternative and Complementary Medicine, 13(6), 651-658.

Chiesa, A., Calati, R., \& Serretti, A. (2011). Does mindfulness training improve cognitive abilities? A systematic review of neuropsychological findings. Clinical Psycholy Review, 31, 449-464.

Chiesa, A., \& Serretti, A. (2011). Mindfulness-based interventions for chronic pain: a systematic review of the evidence. Journal of Alternative and Complementary Medicine, 17(1), 83-93.

Cosme, D., \& Wiens, S. (2015). Self-reported trait mindfulness and affective reactivity: A motivational approach using multiple psychophysiological measures. PLoS ONE, 10(3), e0119466. doi:10.1371/journal.pone.0119466 
Craig, A. D. (2002). How do you feel? Interoception: the sense of the physiological condition of the body. Nature reviews. Neuroscience, 3(8), 655-666.

Damasio, A. R. J. (1996). The somatic marker hypothesis and the possible functions of the prefrontal cortex. Phil. Trans. R. Soc. Lond. B, 351(1346), 1413-1420.

De Lafuente, V., \& Romo, R. (2006). Neural correlate of subjective sensory experience gradually builds up across cortical areas. Proceedings of the National Academy of Sciences, 103(39), 14266-14271.

Dehaene, S. (2011). Conscious and nonconscious processes: distinct forms of evidence accumulation? In B. Duplantier \& V. Rivasseau (Eds.), Biological physics (pp. 141168). Basel: Springer.

Dehaene, S. (2018). The error-related negativity, self-monitoring, and consciousness. Perspectives on Psychological Science, 13(2), 161-165.

Dehaene, S., \& Changeux, J. P. (2004). Neural mechanisms for access to consciousness. In M. Gazzaniga (Ed.), The cognitive neurosciences III (pp. 1145-1158). Cambridge, MA: MIT Press.

Dehaene, S., \& Changeux, J. P. (2011). Experimental and theoretical approaches to conscious processing. Neuron, 70(2), 200-227.

Dehaene, S., Changeux, J. P., Naccache, L., Sackur, J., \& Sergent, C. (2006). Conscious, preconscious, and subliminal processing: a testable taxonomy. Trends in Cognitive Sciences, 10(5), 204-211.

Dehaene, S., Izard, V., Spelke, E., \& Pica, P. (2008). Log or linear? Distinct intuitions of the number scale in Western and Amazonian indigene cultures. Science, 320(5880), 12171220. doi: $10.1126 /$ science. 1156540

Delgado-Pastor, L. C., Perakakis, P., Subramanya, P., Telles, S., \& Vila, J. (2013). Mindfulness (Vipassana) meditation: effects on P3b event-related potential and heart $\begin{array}{llll}\text { rate } & \text { variability. } & \text { Int } & \text { Psychophysiol, }\end{array}$ doi:10.1016/j.ijpsycho.2013.07.006

Dennis, T. A., \& Hajcak, G. (2009). The late positive potential: a neurophysiological marker for emotion regulation in children. Journal of child psychology and psychiatry, 50(11), 1373-1383.

Di Gregorio, F., Steinhauser, M., \& Maier, M. E. (2016). Error-related brain activity and error awareness in an error classification paradigm. NeuroImage, 139, 202-210.

Donkers, F. C. L., \& Van Boxtel, G. J. M. (2004). The N2 in go/no-go tasks reflects conflict monitoring not response inhibition. Brain and Cognition, 56(2), 165-176.

Dorjee, D., Lally, N., Darrall-Rew, J., \& Thierry, G. (2015). Dispositional mindfulness and semantic integration of emotional words: Evidence from event-related brain potentials. Neurosci Res, 97, 45-51. doi:10.1016/j.neures.2015.03.002

Dunn, B. D., Galton, H. C., Morgan, R., Evans, D., Oliver, C., Meyer, M., . . . Dalgleish, T. (2010). Listening to your heart: How interoception shapes emotion experience and intuitive decision making. Psychological Science, 21(12), 1835-1844.

Egan, R. P., Hill, K. E., \& Foti, D. (2018). Differential Effects of State and Trait Mindfulness on the Late Positive Potential. Emotion, 18(8), 1128-1141.

Endrass, T., Reuter, B., \& Kathmann, N. (2007). ERP correlates of conscious error recognition: aware and unaware errors in an antisaccade task. European Journal of Neuroscience, 26(6), 1714-1720.

Eichel, K., \& Stahl, J. (2016). The Role of Mindfulness and Emotional Stability in Error Detection. Mindfulness, 8(2), 311-324. doi : 10.1007/s12671-016-0601-1 
Falkenstein, M., Hohnsbein, J., Hoormann, J., \& Blanke, L. (1991). Effects of crossmodal divided attention on late ERP components. II. Error processing in choice reaction tasks. Electroencephalography and Clinical Neurophysiology, 78, 447-455.

Falkenstein, M., Hoormann, J., Christ, S., \& Hohnsbein, J. (2000). ERP components on reaction errors and their functional significance: a tutorial. Biological Psychology, 51(2), 87-107.

Farb, N., Daubenmier, J., Price, C. J., Gard, T., Kerr, C., Dunn, B. D., . . . Mehling, W. E. (2015). Interoception, contemplative practice, and health. Front Psychol, 6, 763. doi:10.3389/fpsyg.2015.00763

Fjorback, L. O., Arendt, M., Ørnbøl, E., Fink, P., \& Walach, H. (2011). Mindfulness-Based Stress Reduction and Mindfulness-Based Cognitive Therapy-a systematic review of randomized controlled trials. Acta Psychiatrica Scandinavica, 124(2), 102-119.

Folstein, J. R., \& Van Petten, C. (2008). Influence of cognitive control and mismatch on the N2 component of the ERP: a review. Psychophysiology, 45(1), 152-170.

Foti, D., \& Hajcak, G. (2008). Deconstructing reappraisal: Descriptions preceding arousing pictures modulate the subsequent neural response. Journal of Cognitive Neuroscience, 20(6), 977-988.

Gaillard, R., Dehaene, S., Adam, C., Clémenceau, S., Hasboun, D., Baulac, M., . . Naccache, L. (2009). Converging intracranial markers of conscious access. Plos Biology, 7(3), e1000061. doi:10.1371/ journal.pbio.1000061

Garland, E. L., Froeliger, B., \& Howard, M. O. (2015). Neurophysiological evidence for remediation of reward processing deficits in chronic pain and opioid misuse following treatment with Mindfulness-Oriented Recovery Enhancement: exploratory ERP findings from a pilot RCT. J Behav Med, 38(2), 327-336. doi:10.1007/s10865-0149607-0

Garland, E. L., Gaylord, S. A., \& Fredrickson, B. L. (2011). Positive reappraisal mediates the stress-reductive effects of mindfulness: An upward spiral process. Mindfulness $(N Y)$, 2(1), 59-67.

Gehring, W. J., Goss, B., Coles, M. G. H., Meyer, D. E., \& Donchin, E. (1993). A neural system for error detection and compensation. Psychological Science, 4, 385-390.

Goldberg, S. B., Tucker, R. P., Greene, P. A., Davidson, R. J., Wampold, B. E., Kearney, D. J., \& Simpson, T. L. (2018). Mindfulness-based interventions for psychiatric disorders: A systematic review and meta-analysis. Clinical Psychology Review, 59, 52-60.

Gosseries, O., Demertzi, A., Noirhomme, Q., Tshibanda, J., Boly, M., Op de Beeck, M., .. . De Tiege, X. (2008). Functional neuroimaging (fMRI, PET and MEG): what do we measure? Revue médicale de Liège, 63(5-6), 231-237.

Guendelman, S., Medeiros, S., \& Rampes, H. (2017). Mindfulness and emotion regulation: Insights from neurobiological, psychological, and clinical studies. Frontiers in Psychology, 8, 220. doi:10.3389/fpsyg.2017.00220

Hajcak, G., \& Nieuwenhuis, S. (2006). Reappraisal modulates the electrocortical response to unpleasant pictures. Cognitive, Affective and Behavioral Neuroscience, 6(4), 291-297.

Hanley, A. W., Mehling, W. E., \& Garland, E. L. (2017). Holding the body in mind: Interoceptive awareness, dispositional mindfulness and psychological well-being. Journal of Psychosomatic Research, 99, 13-20.

Ho, N. S. P., Sun, D., Ting, K. H., Chan, C. C. H., \& Lee, T. M. C. (2015). Mindfulness trait predicts neurophysiological reactivity associated with negativity bias: an ERP study. Evidence-Based Complementary and Alternative Medicine, 2015. 
Hobson, N. M., Saunders, B., Al-Khindi, T., \& Inzlicht, M. (2014). Emotion down-regulation diminishes cognitive control: A neurophysiological investigation. Emotion, 14(6), 1014-1027.

Holroyd, C. B., \& Coles, M. G. H. (2002). The neural basis of human error processing: reinforcement learning, dopamine, and the error-related negativity. Psychological Review, 109(4), 679-709.

Holt, D. J., Lynn, S. K., \& Kuperberg, G. R. (2009). Neurophysiological correlates of comprehending emotional meaning in context. Journal of Cognitive Neuroscience, 21(11), 2245-2262.

Hölzel, B. K., Lazar, S. W., Gard, T., Schuman-Olivier, Z., Vago, D. R., \& Ott, U. (2011). How does Mindfulness meditation work? Proposing mechanisms of action from a conceptual and neural perspective. Perspectives on Psychological Science, 6(6), 537559.

Howells, F. M., Ives-Deliperi, V. L., Horn, N. R., \& Stein, D. J. (2012). Mindfulness based cognitive therapy improves frontal control in bipolar disorder: a pilot EEG study. BMC Psychiatry, 12, 15. doi:10.1186/1471-244x-12-15

Howells, F. M., Laurie Rauch, H. G., Ives-Deliperi, V. L., Horn, N. R., \& Stein, D. J. (2014). Mindfulness based cognitive therapy may improve emotional processing in bipolar disorder: pilot ERP and HRV study. Metab Brain Dis, 29(2), 367-375. doi:10.1007/s11011-013-9462-7

Kabat-Zinn, J. (1990). Full catastrophe living: using the wisdom of your body and mind to face stress, pain and illness. New York: Dell Publishing.

Kabat-Zinn, J. (1994). Wherever you go, there you are: Mindfulness meditation in every day life. New York: Hyperion.

Koch, C., Massimini, M., Boly, M., \& Tononi, G. (2016). Neural correlates of consciousness: progress and problems. Nature Reviews Neuroscience, 17(5), 307-321.

Lakey, C. E., Berry, D. R., \& Sellers, E. W. (2011). Manipulating attention via mindfulness induction improves P300-based brain-computer interface performance. J Neural Eng, 8(2), 025019. doi:10.1088/1741-2560/8/2/025019

Larson, M. J., Steffen, P. R., \& Primosch, M. (2013). The impact of a brief mindfulness meditation intervention on cognitive control and error-related performance monitoring. Frontiers in Human Neuroscience, 7(308), 1-12. doi:10.3389/fnhum.2013.00308

Lin, Y., Fisher, M. E., Roberts, S. M. M., \& Moser, J. S. (2016). Deconstructing the emotion regulatory properties of mindfulness: an electrophysiological investigation. Frontiers in Human Neuroscience, 10, 451. doi:10.3389/fnhum.2016.00451

Lindsay, E. K., \& Creswell, J. D. (2018). Mindfulness, acceptance, and emotion regulation: Perspectives from Monitor and Acceptance Theory (MAT). Current opinion in psychology, 28, 120-125.

Lutz, A., Jha, A. P., Dunne, J. D., \& Saron, C. D. (2015). Investigating the Phenomenological Matrix of Mindfulness-related Practices from a Neurocognitive Perspective. The American psychologist, 70(7), 632-658. doi:10.1037/a0039585

Lutz, A., Slagter, H. A., Dunne, J. D., \& Davidson, R. J. (2008). Attention regulation and monitoring in meditation. Trends in Cognitive Sciences, 12(4), 163-169.

Magalhaes, A. A., Oliveira, L., Pereira, M. G., \& Menezes, C. B. (2018). Does Meditation Alter Brain Responses to Negative Stimuli? A Systematic Review. Frontiers in Human Neuroscience, 12, 448. doi:10.3389/fnhum.2018.00448

Malinowski, P. (2013). Neural mechanisms of attentional control in Mindfulness Meditation. Frontiers in Neuroscience, 7(8). 
Malinowski, P., Moore, A. W., Mead, B. R., \& Gruber, T. (2017). Mindful aging: the effects of regular brief mindfulness practice on electrophysiological markers of cognitive and affective processing in older adults. Mindfulness $(N \quad Y), \quad 8(1)$, 78-94. doi:10.3389/fnins.2013.00008

Manuello, J., Vercelli, U., Nani, A., Costa, T., \& Cauda, F. (2016). Mindfulness meditation and consciousness: An integrative neuroscientific perspective. Consciousness and Cognition, 40, 67-78.

Marti, S., Sigman, M., \& Dehaene, S. (2012). A shared cortical bottleneck underlying Attentional Blink and Psychological Refractory Period. NeuroImage, 59(3), 28832898.

Mehling, W. E., Gopisetty, V., Daubenmier, J. J., Price, C. J., Hecht, F. M., \& Stewart, A. (2009). Body awareness: construct and self-report measures. PLoS ONE, 4(5), e5614. doi:10.1371/journal.pone.0005614

Mehling, W. E., Price, C., Daubenmier, J. J., Acree, M., Bartmess, E., \& Stewart, A. (2012). The Multidimensional Assessment of Interoceptive Awareness (MAIA). PLoS ONE, 7(11), e48230. doi:10.1371/journal.pone.0048230

Moher, D., Liberati, A., Tetzlaff, J., \& Altman, D. G. (2009). Preferred reporting items for systematic reviews and meta-analyses: the PRISMA statement. Annals of Internal Medicine, 151(4), 264-269.

Moore, A., Gruber, T., Derose, J., \& Malinowski, P. (2012). Regular, brief mindfulness meditation practice improves electrophysiological markers of attentional control. Frontiers in Human Neuroscience, 6(18). doi:10.3389/fnhum.2012.00018

Moore, A., \& Malinowski, P. (2009). Meditation, mindfulness and cognitive flexibility. Conscious Cogn, 18(1), 176-186. doi:10.1016/j.concog.2008.12.008

Muller-Gass, A., Macdonald, M., Schröger, E., Sculthorpe, L., \& Campbell, K. (2007). Evidence for the auditory P3a reflecting an automatic process: elicitation during highly-focused continuous visual attention. Brain Research, 1170, 71-78.

Murphy, P. R., Robertson, I. H., Allen, D., Hester, R., \& O'Connell, R. G. (2012). An electrophysiological signal that precisely tracks the emergence of error awareness. Frontiers in Human Neuroscience, 6, 65. doi:10.3389/fnhum.2012.00065

Nieuwenhuis, S., Ridderinkhof, K. R., Blom, J., Band, G. P. H., \& Kok, A. (2001). Errorrelated brain potentials are differentially related to awareness of response errors: evidence from an antisaccade task. Psychophysiology, 38(5), 752-760.

Nieuwenhuis, S., Yeung, N., Van Den Wildenberg, W., \& Ridderinkhof, K. R. (2003). Electrophysiological correlates of anterior cingulate function in a go/no-go task: effects of response conflict and trial type frequency. Cognitive, Affective and Behavioral Neuroscience, 3(1), 17-26.

Norris, C. J., Creem, D., Hendler, R., \& Kober, H. (2018). Brief mindfulness meditation improves attention in novices: Evidence from ERPs and moderation by neuroticism. Frontiers in Human Neuroscience, 12, 315. doi:10.3389/fnhum.2018.00315

Overbeek, T. J. M., Nieuwenhuis, S., \& Ridderinkhof, K. R. (2005). Dissociable components of error processing: on the functional significance of the Pe vis-à-vis the ERN/Ne. Journal of Psychophysiology, 19(4), 319-329.

Perri, R. L., Berchicci, M., Bianco, V., Quinzi, F., Spinelli, D., \& Di Russo, F. (2018). Awareness of perception and sensory-motor integration: ERPs from the anterior insula. Brain Struct Funct, 223(8), 3577-3592. doi:10.1007/s00429-018-1709-y

Polich, J. (2007). Updating P300: an integrative theory of P3a and P3b. Clin Neurophysiol, 118(10), 2128-2148. doi:10.1016/j.clinph.2007.04.019 
Pollatos, O., Kirsch, W., \& Schandry, R. (2005). Brain structures involved in interoceptive awareness and cardioafferent signal processing: a dipole source localization study. Human Brain Mapping, 26(1), 54-64.

Pollatos, O., \& Schandry, R. (2004). Accuracy of heartbeat perception is reflected in the amplitude of the heartbeat evoked brain potential. Psychophysiology, 41(3), 476-482.

Quaglia, J. T., Goodman, R. J., \& Brown, K. W. (2016). Trait mindfulness predicts efficient top-down attention to and discrimination of facial expressions. Journal of Personality, 84(3), 393-404.

Rochet, N., Spieser, L., Casini, L., Hasbroucq, T., \& Burle, B. (2014). Detecting and correcting partial errors: Evidence for efficient control without conscious access. Cognitive, Affective, \& Behavioral Neuroscience, 14(3), 970-982.

Salisbury, D. F., Griggs, C. B., Shenton, M. E., \& McCarley, R. W. (2004). The NoGo P300 'anteriorization' effect and response inhibition. Clinical Neurophysiology, 115(7), 1550-1558.

Saunders, B., Rodrigo, A. H., \& Inzlicht, M. (2016). Mindful awareness of feelings increases neural performance monitoring. Cognitive, Affective and Behavioral Neuroscience, 16(1), 93-105.

Schandry, R., Sparrer, B., \& Weitkunat, R. (1986). From the heart to the brain: a study of heartbeat contingent scalp potentials. International Journal of Neuroscience, 30(4), 261-275.

Schoenberg, P. L., Hepark, S., Kan, C. C., Barendregt, H. P., Buitelaar, J. K., \& Speckens, A. E. (2014). Effects of mindfulness-based cognitive therapy on neurophysiological correlates of performance monitoring in adult attention-deficit/hyperactivity disorder. Clin Neurophysiol, 125(7), 1407-1416. doi:10.1016/j.clinph.2013.11.031

Schooler, J. W. (2002). Re-representing consciousness: dissociations between experience and meta-consciousness. Trends Cogn Sci, 6(8), 339-344.

Schupp, H. T., Cuthbert, B. N., Bradley, M. M., Cacioppo, J. T., Ito, T., \& Lang, P. J. (2000). Affective picture processing: the late positive potential is modulated by motivational relevance. Psychophysiology, 37(2), 257-261.

Schupp, H. T., Flaisch, T., Stockburger, J., \& Junghöfer, M. (2006). Emotion and attention: event-related brain potential studies. Progress in Brain Research, 156, 31-51.

Segal, Z., Williams, M., \& Teasdale, J. (2012). Mindfulness-based cognitive therapy for depression. New York: Guilford.

Shadlen, M. N., \& Kiani, R. (2011). Consciousness as a decision to engage. In S. Dehaene \& Y. Christen (Eds.), Characterizing consciousness: from cognition to the clinic? (pp. 27-46). Berlin Heidelberg: Springer-Verlag.

Slagter, H. A., Lutz, A., Greischar, L. L., Francis, A. D., Nieuwenhuis, S., Davis, J. M., \& Davidson, R. J. (2007). Mental training affects distribution of limited brain resources. Plos Biology, 5(6), e138. doi:10. 1371/journal.pbio.0050138

Smart, C. M., \& Segalowitz, S. J. (2017). Respond, don't react: The influence of mindfulness training on performance monitoring in older adults. Cognitive, Affective and Behavioral Neuroscience, 17(6), 1151-1163.

Smart, C. M., Segalowitz, S. J., Mulligan, B. P., Koudys, J., \& Gawryluk, J. R. (2016). Mindfulness training for older adults with subjective cognitive decline: results from a pilot randomized controlled trial. Journal of Alzheimer's Disease, 52(2), 757-774.

Smid, H. G. O. M., Mulder, G., \& Mulder, L. J. M. (1990). Selective response activation can begin before stimulus recognition is complete: a psychophysiological and error analysis of continuous flow. Acta Psychologica, 74, 169-201. 
Sobolewski, A., Holt, E., Kublik, E., \& Wrobel, A. (2011). Impact of meditation on emotional processing: a visual ERP study. Neurosci Res, 71(1), 44-48. doi:10.1016/j.neures.2011.06.002

Steinhauser, M., \& Yeung, N. (2010). Decision processes in human performance monitoring. Journal of Neuroscience, 30(46), 15643-15653.

Tecce, J. J. (1972). Contingent negative variation (CNV) and psychological processes in man. Psychological Bulletin, 77(2), 73-108.

Tecce, J. J., \& Cattanach, L. (1993). Contingent negative variation (CNV). In E. Niedermeyer \& F. H. L. da Silva (Eds.), Electroencephalography: basic principles, clinical applications, and related fields: Lippincott Williams and Wilkins.

Teper, R., \& Inzlicht, M. (2012). Meditation, mindfulness and executive control: the importance of emotional acceptance and brain-based performance monitoring. Social Cognitive and Affective Neuroscience, 8(1), 85-92.

Thompson, R. A. (1994). Emotion regulation: A theme in search of definition. Monographs of the society for research in child development, 59(2-3), 25-52.

Treves, I. N., Tello, L. Y., Davidson, R. J., \& Goldberg, S. B. (2019). The relationship between mindfulness and objective measures of body awareness: A meta-analysis. Scientific Reports, 9(1), 1-12.

Ullsperger, M., Danielmeier, C., \& Jocham, G. (2014). Neurophysiology of performance monitoring and adaptive behavior. Physiological Reviews, 94(1), 35-79.

Uusberg, H., Uusberg, A., Talpsep, T., \& Paaver, M. (2016). Mechanisms of mindfulness: The dynamics of affective adaptation during open monitoring. Biological Psychology, 118, 94-106.

Valenzuela-Moguillansky, C., Reyes-Reyes, A., \& Gaete, M. I. (2017). Exteroceptive and interoceptive body-self awareness in fibromyalgia patients. Frontiers in Human Neuroscience, 11, 117. doi:10.3389/fnhum.2017.00117

Walter, W. G., Cooper, R., Aldridge, V. J., McCallum, W. C., \& Winter, A. L. (1964). Contingent negative variation: an electric sign of sensori-motor association and expectancy in the human brain. Nature, 203(4943), 380-384.

Wenk-Sormaz, H. (2005). Meditation can reduce habitual responding. Alternative therapies in health and medicine, 11(2), 42-59.

Winter, D. A. (1995). Human balance and posture control during standing and walking. Gait and Posture, 3(4), 193-214.

Zelano, C., Jiang, H., Zhou, G., Arora, N., Schuele, S., Rosenow, J., \& Gottfried, J. A. (2016). Nasal respiration entrains human limbic oscillations and modulates cognitive function. Journal of Neuroscience, 36(49), 12448-12467. 